\title{
MAINSTREAMING PUBLIC TRUST FOR AGROBIOTECHNOLOGY DEVELOPMENT: PRELIMINARY FINDINGS FROM INDONESIA ${ }^{1}$
}

\author{
Rachmat Hidayat ${ }^{2}$ Tree Setiawan Pamungkas ${ }^{3}$ Lukman Wijaya Baratha ${ }^{4}$ Ahmad Munif Mubarok
}

\begin{abstract}
This article aims to identify the public trust on the application of Agriculture biotechnology-based products in Indonesia, specifically in the eastern part of East Java Province, which is knowns as Horseshoe region-ex Besuki district. Further, this article will focuses on farmers impediment and their discontent facing the challenges of GM Crops companies for mainstreaming their products in their locality. This article will also expand the discussion on the urgency for local government governance for a sustainable regulatory policy which forbids the rudimentary practice of bad corporate governance Genetically modified (GM) crops in the locality
\end{abstract}

Keyword: Public Trust, Agrobiotechnology Farmers, Policy

\section{Introduction}

The growth of the agricultural industry in the former Besuki residence ${ }^{6}$, which is known as the Horseshoe region of the eastern part of East Java, right from the outset has been inseparable from the development of society in establishing and adjusting their social structure aimed at achieving the imagination of modernity they chose. Challenges and hopes, which are always omnipresent in the effort to achieve these goals, are stranded without interruption to the changing patterns of agriculture and social relations that govern them. As such, the development in one link within the field of agriculture in the Horseshoe region has a fundamental meaning to the institutional structure and cognition that governs how the society lives. One link from the agricultural sector is the application of agricultural biotechnology. Agricultural biotechnology is without a doubt a phenomenon that is no longer considered novel by society, but for decades it has sometimes become a temporary stumbling block to the formation of agricultural patterns that synergize with the economic and social demands of the community. Biotechnology offers the potential in increasing agricultural productivity, food security, and food sustainability (Godfray et al., 2010; Rosegrant \& Cline, 2003).

In the writer' perspectives, the application of biotechnology is not viewed in terms of its engineering technique, which strongly pertains to the domain of biological science. However, researchers make biotechnology only an effect, where the cause of its existence as

${ }^{1}$ The research conducted and supported by Islamic Development Bank (IsDB) funding for the Development of University of Jember as Center of Excellence for Biotechnology of Agriculture and Health 2018.

2 Lecturer Public Administration Dept, Postgraduate Administrative study Program Faculty of Social and Political Science University of Jember, email: rachmat.hidayat@unej.ac.id

${ }^{3}$ Lecturer Public Administration Dept, Faculty of Social and Political Science University of Jember,email: tree.sp.fisip@unej.ac.id

${ }^{4}$ Lecturer Sociology Dept, Faculty of Social and Political Science University of Jember, email: lukman.fisip@unej.ac.id

${ }^{5}$ Lecturer Social Welfare Dept, Faculty of Social and Political Science University of Jember, email: munif.fisip@gmail.com

${ }^{6}$ Ex Besuki Residence referring to four District in the eastern Part of East Java; Jember, Situbondo, Bondowoso and Banyuwangi 
well as its application lies in the social relations of the people who live in the Horseshoe community itself. Through this perspective, we are able to see other aspects concerned with the existence of agricultural biotechnology. Not only is polemic about the quality of the biotechnology seed products worth taking into account, but also more attention has been drawn to why the weakness of the biotechnology application actually opens up aspects of systematic weaknesses for the implementation of social and public policies. What is more, it can also unearth the management failure of an agrarian society in orienting itself out of the crisis it foresees; namely the food crisis and the government's failure to manage agriculture.

In this study, we did not merely present data to measure the level of objectivity of our research. However, the study also parsed the data to project the causality on resultant conditions in the future, while the causes of these conditions are found based on today's phenomenon. Nevertheless, that does not mean that we only produce a line of linear causalities which at some point are read as an iron law of the development of the Horseshoe community. Especially, this is the case when the cause shows the direct link between the policy orientation of the regional government and the orientation of agricultural development. Through the design of the scheme that we describe at the end, we hope to shed lights on the formulation of local government policies, projected to get out of confining linearity that leads to decades of deadlock and polemic traps in the Horseshoe region.

The idea must be understood as an outlook which connects the social role of farmers in modern society. Also, with respect to the structure of modern society itself, deploying government policy may serve as a catalyst for the public emancipatory agenda. This situation is characterized by the ability of the agriculture industry to manage itself sharply to meet the demands in the community. By contrast, the acceptance of the agricultural industrial mechanism in the ex Besuki districts is more inclined to the acceptance of how the use of techniques is claimed to be modern efforts, rather than simultaneously pondering the emancipatory aspects of the existence of these techniques in society.

The lack of social imagination of the community on agricultural techniques that are fundamentally dependent on industrial mechanisms can seem like a classic formula for agricultural involution. Given that there is a seemingly organized chaos, there are utterly no symptoms which portray efforts to improve balance between the acceptance of agricultural technology that continues to be updated with regard to the farmers' social and economic patterns. The absence of a balance of social and economic aspects with agricultural technology in these assumptions appears to be a natural pattern that is taken for granted.

However, if we want to take this into account with broader perspective, particularly with the consequences manifesting that we will have a dramatic picture, then we are living in the scope of third world agriculture; we always assume that the application of agricultural technology is a promising endeavor for our future. Ironically, this endeavor has passed centuries and decades, dramatically leaving us constantly grapple with the "adjustment" stage. From positivist spectacles, we can call it "still being in the transition stage". A transitional era that has lasted for several generations along with memories of the promise gradually disappearing, followed by the disappearance of farmers one by one and the stable pattern of agriculture.

The worrying reality picture of Jember and Bondowoso farmers who get worse by this situation is even exacerbated by their hurdles in hiring farm laborers when the planting 
and harvesting period commences. Unknown to farmers, the changing social structure that has changed the reality around them, including themselves, and the difficulty of finding farm laborers has become typical hardship. This becomes even more serious as the farmers get older, but they have nobody in their families to become their successors. On the other hand, the structure of agrarian rural communities has been eroding, which lays the basis of social legitimacy for the existence of Indonesian society in general. These two entities imply that villages in the Horseshoe region have made themselves "urban". However, along with these changes, the most fundamental aspect of the change is the increasingly marginalized social role of farmers in social change in the Horseshoe region. Therefore, when we look at this general picture, the question we need to address is "Do the efforts to improve the quality and quantity of production in the agricultural community still need to strengthen public trust in their products and innovations?" especially when the existing conditions do not progress towards the establishment of a social mechanism that benefits many parties involved.

Therefore, in this study, we delved into the consequences of applying biotechnology as an embodiment of efforts to change the farming techniques of Horseshoe society, although we know that in general the application of biotechnology has been there for quite some time. In a social setting, however, a change in technique without any attempt to change the pattern of target community will accrue sustainable positive benefits. Simply put, the distance created between the existence of changes in production will not be able to generate sustainable maximum capacity for the structure sustainability of the people who use the technology.

Therefore in this study, we developed the aspects discussed by Castoriadis (1997) about technological innovation (teukein). We also aimed at measuring its impact on the character of the legitimacy dimension according to Habermas (1975), which encompass the dimensions of rationality, economics, and motivation. Both perspectives are operative because public confidence of farmers in industrial agricultural patterns has declined. Alatas (1988) points out the loss of the farmer community's trust, which portrays a stereotype of farmers and the entire community in Java island during the colonial era being seen as lazy natives. The exploitation of rice fields at that time could only benefit government and industry, in the perspective of the progress of agricultural management. Farmers refuse to accept this aspect of change due to disrupted crop yields. This historical aspect basically touches the moral dimension of the farmer to changes in agricultural patterns. We hope to obtain a special picture of the farmers' trust, industry, and the government on changes in their agricultural techniques that use agricultural biotechnology. By implication, that also reveals their agricultural patterns socially.

\section{The Agrobiotechnology Policy at local level}

Agriculture should no longer be a realm where farmers are accorded with a subordinate social position in the development of Horseshoe society. This should not be interpreted in the sense that the application of technology does not touch upon the existence of farmers. However, it should pertain more to how the understanding of technological development and accrue the positive results of these developments to benefit the social position of farmers. 
One typical reason that is still confined to the stereotype of farmers is that they are part of the traditional past structure. Making each of the most basic assumptions for changes in agricultural patterns is not intended to change the farmers' mindset. As a corollary, that repressive elements in the application of agricultural biotechnology do not purposively comply with agricultural policies or, at some point, inherently attempt to overlook the policies that can bridge problem solving. As a result, when farmers have used biotechnology for quite some time, they do not have the capacity to fully assess how their entire agricultural pattern has changed.

The current situation has put Horseshoe society is in the same scope, but that does not mean that the consequences will follow naturally and evolutionarily as China can achieve results in such a way. A willingness is still called upon, be it political or economic one to see the ability to achieve equal results. Or, it may be otherwise an effort to uncover the path pioneered by the delightful promise of modernity in Indonesia. The fundamental principle in this regard will have to be based on developing a different mindset towards the classical conditions of the Horseshoe agrarian society, that is the recognition that farmers are not a traditional profession. This job, like any types of work created by the industrial era, stand and present as a force that supports industrialization itself. Then the industrial power that arises in the Horseshoe region is not a destructive aspect of the societal structure. Rather, it appears as an endeavor to open the potential of this community.

If this principle has not yet arisen in today's circumstance of the Horseshoe region, this will not emerge not due to a permanent cause driving agricultural biotechnology to cut the path of traditional farmers' relations with seeds and fertilizer. Pathway between farmers and government, the path between them and industry, and innovation in regional agricultural knowledge, which are all robustly interrelated, are the most complete assertion in finding and determining the development direction of Horseshoe industry and agriculture. The descriptions below are compiled to portray the interlinked potentialities.

First, it is imperative to scrutinize permanent scheme creation that has long-term projections regarding Horseshoe farming development plans. This is essential to ensure that there is a protection against the orientation of increasing the quantity and quality of food in Horseshoe communities. The main principles of biotechnology operative through the existing need for market share and innovation inevitably always bring innovators closer to the industry agenda. However, such a principle can end up as a double-edged sword if its orientation is solely relying on the mere presence of industrial profits. The presence of biotechnology agricultural products has changed the agricultural landscape of Horseshoe region to produce a scheme that is quite reactive to the market demand. The staple food supply of the people falls with the narrowing of rice fields to grow staple commodities. Instead of actively following market share, farmers are easily attracted by the types of plants assumed to be rarely planted.

This is inherently reflected in the meaning of agribusiness in the minds of farmers. Instead, they have never pondered planting aimed to improve quality and quantity. The only market logic they understand is that only replacing the seeds they plant in the field with different seeds, such as fruit or other plants, is pivotal to meet market demand. Instead, they are at a stage where their trust in the production line that will use their crops depends on new parties who often must depend on the distribution line from upstream to 
downstream. As a result, it can be expected that farmers become quite vulnerable to competition among producers from agriculture-based industries. By creating a permanent scheme on agricultural development, the diversity of plant species in farmers' fields does not rely on unpredictable conditions and volatile market. However, it relies on the structures supported by government and industry that follow the path of government policy.

Finally, as a binding on this subject matter is the use of knowledge that grows and has direct ties to the conditions of the Horseshoe farming. At this point, we come to the most basic meaning of how public trust in biotechnology Horseshoe regions must reach balance. The agricultural labor forces are getting older and the attractiveness continues to decline among the people who work as farmers. Inevitably, these phenomena are also influenced by the mindset of the young generation in the Horseshoe region. Access to the education they get practically provides an amazing picture of modernity that is ironically not present in their own society. Modernity is thus imagined through a distance, where it now instills a kind of combined consciousness from various pieces which they do not understand. The true meaning of this kind of awareness is the isolation from expectations measured by its current position and efforts to set a gap between the present and the future.

Mahbubani (2009) describes an interesting turning point about how $21^{\text {st }}$ century Asian universities which now have a lot of experts who have been "learning" and gaining experience in the West over the past few years. These intellectuals have now returned, which not only means the return of the individual to their homeland, but also the return of the main focus of knowledge about Asia. The turning point of this knowledge includes a rereading of the interpretation of Asian society about them (Asian scholars) and what the West thinks of them. The newly developed image of these Asians is so much different to that present in the previous few centuries. Therefore, the incorrect Western picture of the Asian agricultural community, as revealed by Alatas (1988), now looks funny and naive.

All in all, how do we see this in the Horseshoe community? If we briefly delve into the context of biotechnology, then what we can see is the presence of efforts to get closer to what was previously represented as a Western discourse on agricultural innovation. The West in this case is manifested by a condition that is distant from the social reality, where this understanding does not lie in all the technical devices accompanying the presence of agricultural biotechnology. Instead, it lies in moral, economic, and social mismatches. This certainly comes from a long history of early agricultural innovation that builds the reason for industrial binary opposition with agricultural traditionalism, which unfortinately we cannot describe in this paper. ${ }^{i}$

Nevertheless, the instrument of knowledge about agriculture is practically in the hand of the Horseshoe community. So that the emergence of biotechnology can basically be pursued as a knowledge innovation in the region, where numerous universities are established. The distance between the concept and the historical context is not as far away as science has to look at the Western context so far. Therefore, it is important to respond to all of these links with efforts to build agricultural innovation through biotechnology Moreover, it is important to bring the idea of modernity among the rural youths who have access to education, particularly pertinent to the true meaning of Indonesia's modernity through agriculture. In this regard, public trust in agricultural biotechnology does not stop at technical innovation, but it also accrues and maintains the social structure of the Horseshoe 
agrarian society as well as the participatory pattern that links education, agriculture, and industry.

These four aspects, when linked together, will raise a level of participatory public trust, compared to the schemes that have been seen. Farmers will no longer be under duress that demands them strive to get out of harm through the acceptance of agricultural advertisements that presume their product innovation as a way out that is easily accepted by short-term reasoning. Likewise, their equal social position in the face of urban types of work will be able to clog up the taps of migrant workers from all villages and the availability of young farmers in the Horseshoe region. On the local government side, the implementation of their policies will be measured into stages, rather than disconnections and delirium regulation traps. On the industrial side, policies born from therefrom will satisfy all environmental and social aspects of the Horseshoe community, without making them merely retail agents or distributors of agricultural products.

Therefore, our emphasis on the importance of agricultural biotechnology is the presence of a deliberative policy formulation. In this regard, the demands driven by the empirical reality of the Horseshoe community are not interpreted as demands that presuppose a confusing unilateral agreement and involves all elements of agricultural biotechnology support. However, as Habermas said, this reality relies on the life experience of all types of social status and the division of public labor, a meaning of life which he calls lebenswelt (Hardiman, 2009). A meaningful technology coupled with its innovation is not an instrument of user alienation against him. However, it manifests a moral, economic and social belief, and its acceptance in the societal development, which will automatically involve them to gain relative benefits that can be enjoyed without nullifying the social roots where it exists and its historicity.

\section{Policy Option for Local Agricultural Biotechnology Development}

After identifying problems and obstacles to developing public trust in the development of biotechnology products, researchers have formulated several policy alternatives that can be applied by stakeholders in increasing public confidence in biotechnology products. Policy option for local biotechnology development mainly attributed to the models and the inputs from various stakeholders of the Horseshoe region-ex Besuki districts as well as academics in the field of biotechnology from various scientific perspectives.

The study concludes 4 (four) policy alternatives for the development of Agricultural Biotechnology in the Horseshoe which include the followings.

1) Downstreaming Agricultural Biotechnology Innovations

Downstreaming biotechnology innovation policy is related to the implementation process and utilization of agricultural biotechnology innovation. Agricultural biotechnology product innovations carried out by academics and researchers will soon be industrialized, so the innovations in agricultural biotechnology product will be quickly put at play.

2) Establishing Institution and Governance of Agricultural Biotechnology

The choice of institutional policies and governance of agricultural biotechnology is related to institutional arrangements and governance both at the central government level and regional governments that hold the authority in agricultural biotechnology. 
Strengthening and restructuring agricultural biotechnology institutions are carried out in an effort to support biotechnology products and maintain the wealth of local varieties.

3) Acceleration of Farmers' Social Capital

The acceleration of farmers 'social capital is related to strengthening the social capital of biotechnology farmer groups, alleviating the dependence of farmers from middlemen, and strengthening farmers' ability to manage their agricultural products.

4) The Acceptability of Agricultural Biotechnology

The acceptability policy for agricultural biotechnology is related to the socialization and campaign for the use of safe biotechnology products as an attempt to increase the productivity of agricultural products.

For Modelling of the Policy alternative above, we employ an Analytical Hierarchy Process (AHP) to produce the fittest policy option for the development of Agricultural Biotechnology in the Horseshoe region. In this research, AHP employs pairwise comparisons among policy option, chosen based on expert recommendation, to determine priority scales (Saaty \& Vargas, 2001) of the possible policy option for adoption.

The results reveal policy priorities of agricultural biotechnology development policy in the Horseshoe region includes the synergy of agricultural biotechnology governance at the local level. This involves a balanced participation among the regional government, the private sector, and the society. A governance synergy and a balanced participation between local government, private sectors and the society in the Horseshoe regions must be taken into account in the attempt for building a public trust for the development of Biotechnology for agricultural application.

\section{Conclusion}

This paper has discussed the obstacles and problems related to the legitimacy of public trust in biotechnology products are evident. First, all farms in the Horseshoe region are seen as the market for industrial biotechnology product. Second, farmers relatively avoid risks in using biotechnology products based on market information rather than first-hand experience. Third, the existing polemic concerned with the use of biotechnology in Horseshoe region obstructs local governments to deal with market competition among agricultural biotechnology seed producers.

At the policy level, the problems found in the study are related to public trust in biotechnology products. First, there is permanent scheme creation that has long-term projections about Horseshoe farming development plans. Second, protection of agricultural market prices also becomes one issue. Third, industrialization projects must be known by the public at large. Finally, encompassing the overall issues is the use of knowledge that grows and has a direct bond with the farming conditions of Horseshoe community.

To increase public confidence in biotechnology products, Our findings suggest a model of policy option that leans heavily on the synergy of agricultural biotechnology governance at the local level, which includes a balanced participation among the regional government, the private sector, and the society at local level, which is seemingly detach from each other in the Horseshoe regions. 


\section{Bibliography}

Alatas, H. (1988). Mitos pribumi malas: citra orang Jawa, Melayu dan Filipina dalam kapitalisme kolonial: Lembaga Penelitian, Pendidikan dan Penerangan Ekonomi dan Sosial.

Baxter, J., \& Greenlaw, K. (2005). Explaining perceptions of a technological environmental hazard using comparative analysis. Canadian Geographer/Le Géographe canadien, 49(1), 61-80.

Castoriadis, C. (1997). The imaginary institution of society: Mit Press.

Cook, G. (2004). Genetically modified language: the discourse of arguments for GM crops and food: Routledge.

Diamond, J. M. (1998). Guns, germs and steel: a short history of everybody for the last 13,000 years: Random House.

Frewer, L. (2003). 10. Societal issues and public attitudes towards genetically modified foods. Trends in Food Science E Technology, 14(5-8), 319-332.

Godfray, H. C. J., Beddington, J. R., Crute, I. R., Haddad, L., Lawrence, D., Muir, J. F., . . . Toulmin, C. (2010). Food security: the challenge of feeding 9 billion people. science, 1185383.

Habermas, J. (1975). Legitimation Crisis (Vol. 519): Beacon Press.

Hardiman, F. B. (2009). Demokrasi deliberatif: menimbang negara hukum dan ruang publik dalam teori diskursus Jurgen Habermas: Kanisius.

Huffman, W. E., Rousu, M., Shogren, J. F., \& Tegene, A. (2007). The effects of prior beliefs and learning on consumers' acceptance of genetically modified foods. Journal of Economic Behavior \& Organization, 63(1), 193-206.

Jacobsen, S.-E., Sørensen, M., Pedersen, S. M., \& Weiner, J. (2013). Feeding the world: genetically modified crops versus agricultural biodiversity. Agronomy for sustainable development, 33(4), 651-662.

Jaques, M. (2009). When China rules the world. Allen Lane. London.

Knight, G. R. (2015). Sugar, Steam and Steel: The Industrial Project in Colonial Java, 1830-1850: University of Adelaide Press.

Lankester, T. (2004). 'Asian drama': the pursuit of modernization in India and Indonesia. Asian Affairs, 35(3), 291-304. doi:10.1080/0306837042000303894

Mahbubani, K. (2009). The new Asian hemisphere: The irresistible shift of global power to the East: PublicAffairs.

Paarlberg, R. L. (2001). The politics of precaution: Genetically modified crops in developing countries: Intl Food Policy Res Inst.

Rosegrant, M. W., \& Cline, S. A. (2003). Global food security: challenges and policies. science, 302(5652), 1917-1919.

Saaty, T. L., \& Vargas, L. G. (2001). Models, methods, concepts \& applications of the Analytic Hierarchy Process-Kluwer Academic Publishers: Boston.

Shiva, V. (2016). The violence of the green revolution: Third world agriculture, ecology, and politics: University Press of Kentucky.

\footnotetext{
${ }^{i}$ Diamond (1998) Guns, Germs \& Steel (1998) describe that existentially the emergence of the farmer profession in society has changed the structure of society as a whole. This has been different from those who were previously in the hunting and gathering phase to become a community that maintained and developed natural potential. Diamond explicitly marked the earliest profession of farmers from their efforts to find superior seeds that their culture would develop. This means changing plant ecosystems, selecting superior seeds, and removing seeds that are not superior, and
} 
striving permanently to increase the production quantity. Gradually, this reasoning developed massively into the formation of industrial societies which based their principles on changing the existence and essence of community production on a constant basis, including changes in traditional agricultural patterns. The reason for this industrial society was indeed the reason that the early farmers had, but these days has encompassed a wider perspective and moved quickly. Through this perspective, Diamond has historically demonstrated the linkage and suitability between the existence of simple genetic engineering carried out by farmers and the emergence of industrial-supported agricultural biotechnology.

ii Shiva (2016) for example, was one of those who formulated a binary opposition to industrialization of agriculture in India with respect to the society conditions. Industrialization of (biotechnology) was merely a transfer of technology without the emergence implementation space toward the economic and moral legitimacy of society. Instead, it created destructive impacts on the environment and social groups in the community. Therefore, it did not completely reject the consequences of the agricultural industry. Shiva sued the negative aspects of the industry which were built solely by reasoning and the Western context, because India was different in terms of its goals, ways to interpret agriculture, conservation of nature, and the division of social work. 